


\section{U. S. DEPARTMENT OF COMMERCE}

DANIEL C. ROPER, Secretary

NATIONAL BUREAU OF STANDARDS

LYMAN J. BRIGGS, Director

NATIONAL BUREAU OF STANDARDS MISCELLANEOUS PUBLICATION M123

\section{PRODUCTION OF PRESSBOARD FROM CORNSTALKS}

By

BAKER WINGFIELD, T.R. NAFFZIGER, E. R. WHITTEMORE, C. B. OVERMAN, O. R. SWEENEY, and S. F. ACREE

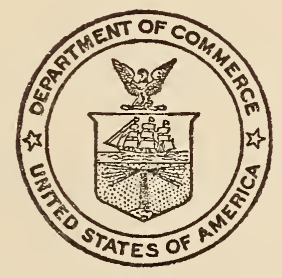

UNITED STATES

GOVERNMENT PRINTING OFFICE

WASHINGTON : 1936 



\title{
PRODUCTION OF PRESSBOARD FROM CORNSTALKS
}

\author{
By Baker Wingfield, T. R. Naffziger, E. R. Whittemore, C. B. Overman, \\ O. R. Sweeney, and S. F. Acree
}

ABSTRACT

A process for the production of pressboard from cornstalks, consisting in stalk preparation, pulping, forming, pressing and drying under pressure, and sizing is outlined.

Stalk preparation by reduction to short lengths and removal of wire and dirt facilitated handling and reduced wear on the machines.

The experimental results showed that boards could be produced with a range of the modulus of rupture from 2,040 to $7,500 \mathrm{lb} / \mathrm{in}^{2}{ }^{2}$ by varying the degree of cooking given the stalks from 0 to $3 \mathrm{hr}$ at $140^{\circ} \mathrm{C}$, in water, followed by a twostage mechanical refining treatment. The two-stage milling was found to be advantageous in producing a uniform pulp.

The pulp was formed into wet mats, which were dried at about $150^{\circ} \mathrm{C}$ under a pressure of about $500 \mathrm{lb} / \mathrm{in}^{2}$. It was found that excess water could be expressed mechanically until only about 60 percent remained in the wet mat, with about 20 -percent loss in strength of the resulting board. This permitted the hot presses to be brought up to pressure more rapidly and probably reduced their steam consumption. An electrical-resistance method was used for determining the minimum drying time of pressboards.

Moisture resistance was obtained by adding emulsions of paraffin or rosin before the mats were formed. However, better sizing could be obtained by treating the finished board with the size dissolved in a suitable solvent.

\section{CONTENTS}

I. Introduction

II. Equipment

III. Experimental manufacture of board

1. Preparation of stalks

2. Pulping

3. Forming

4. Pressing and drying

(a) Initial and final thickness

(b) Initial moisture

(c) Drying

(1) Pressure and temperature.....

(2) Drying time and measurements....

(3) Mechanical aids for the escape of steam...--

5. Sizing for water resistance....

(a) Beater or tank sizing

(b) Wet-mat sizing

(c) Surface sizing

(d) Solvent sizing 


\section{INTRODUCTION}

A series of investigations was started in 1927 by the National Bureau of Standards on the utilization of agricultural wastes. Some of these studies ${ }^{1} 22^{3} 4_{5} 5$ were carried out in cooperation with the Engineering Experiment Station at Iowa State College, Ames, Iowa. The use of cornstalks as a raw material for insulation board has been shown to be feasible by the results obtained from extensive studies carried on by the Bureau in cooperation with the Experiment Station and by the establishment of a commercial plant. This, however, did not provide an outlet for all the available raw material, and pressboard seemed to promise a further means of using cornstalks.

Pressed boardlike materials have come into use in recent years for bookbinding; electrical insulation; panels for walls, furniture, automobiles, airplanes, and an interior finish for buildings; forms for concrete; floor covering; etc. They are made commercially from wood chips, sulfite wood-pulp screenings, bagasse, etc., in slects $1 / 5$ to $1 / 3$ in. in thickness and generaliy $4 \mathrm{ft}$ in width and $8 \mathrm{ft}$ in length. The boards have one smooth surface and one which shows the imprint of the screen used to facilitate the escape of steam during drying.

The first work on pressboard from cornstalks was started in the chemical engineering laboratories at Iowa State College in $1921,{ }^{6}$ and in 1926 a board of greater density than insulating board was obtained by pressing the wet mat in a steam-heated hydraulic press. This board had a clean, smooth surface produced by a highly polished sheet of metal in contact with it during the drying process. In 1924 Castner ${ }^{7}$ was granted the first United States patent covering the production of a good grade of pressed fiber board free from any binding material. In 1926 Sutherland ${ }^{8}$ patented a pressed fiber board to which had been added a suitable binder. Two of the more recent patents are those of Mason ${ }^{9}$ covering a grainless, hard woodboard, and Sweeney ${ }^{10}$ embracing a pressed board from cornstalk pulp or like fibrous material. Conflicting interests in this field have led to patent litigations.

In 1927 Hartford and Richardson, staff members of the National Bureau of Standards stationed at Iowa State College, started to investigate the methods and equipment which would be most suitable for the production of pressboard from cornstalks.

The general procedure for the conversion of cornstalks into pressboard, detailed in the following sections, consists in cutting the stalks into short lengths, reducing this material to fibers in suitable machines (in some cases preceded by a digestion with hot water or with chemicals), and forming the fibers into mats from a water suspension. The fiber mats are then cold-pressed to reduce the quantity of water and dried in a hot press.

\footnotetext{
1 O. R. Sweeney and W. E. Emley. Manufacture of Insulation Board from Cornstalks. Misc. Pub. BS Mi12 (1930).

${ }^{2}$ C. E. Hartford. Manufacture and Properties of a Cellulosic Product (Maizolith) from Cornstalks and Corncobs. Misc. Pub. BS M108 (1930).

3 O. R. Sweeney, C. E. Hartford, R. W. Richardson, and E. R. Whittemore. Experimental Studies on the Production of Insulating Board from Cornstalks. Iowa State College Eng. Experiment Station Bul. 102 (1931).

4 E. R. Whittemore, C. B. Overman, and Baker Wingfield. Separation of Cornstalks into Long Fiber, Pith, and Fines. NBS Misc. Pub. M148 (1935).

5 E. R. Whittemore, C. B. Overman, and Baker Wingfield. Semicommercial drying of pressboard by Measuring Its Electrical Resistance. Ind. Eng. Chem. 27, 831 (1935).

6 See footnote 3.

7 U. S. Pat. 1499291, June 24, 1924.

8 U. S. Pat. 1598260 , August $31,1926$.

- U. S. Pat. 1663505, March 20, 1928.

10 U. S. Pat. 1772502 , August 12, 1930.
} 


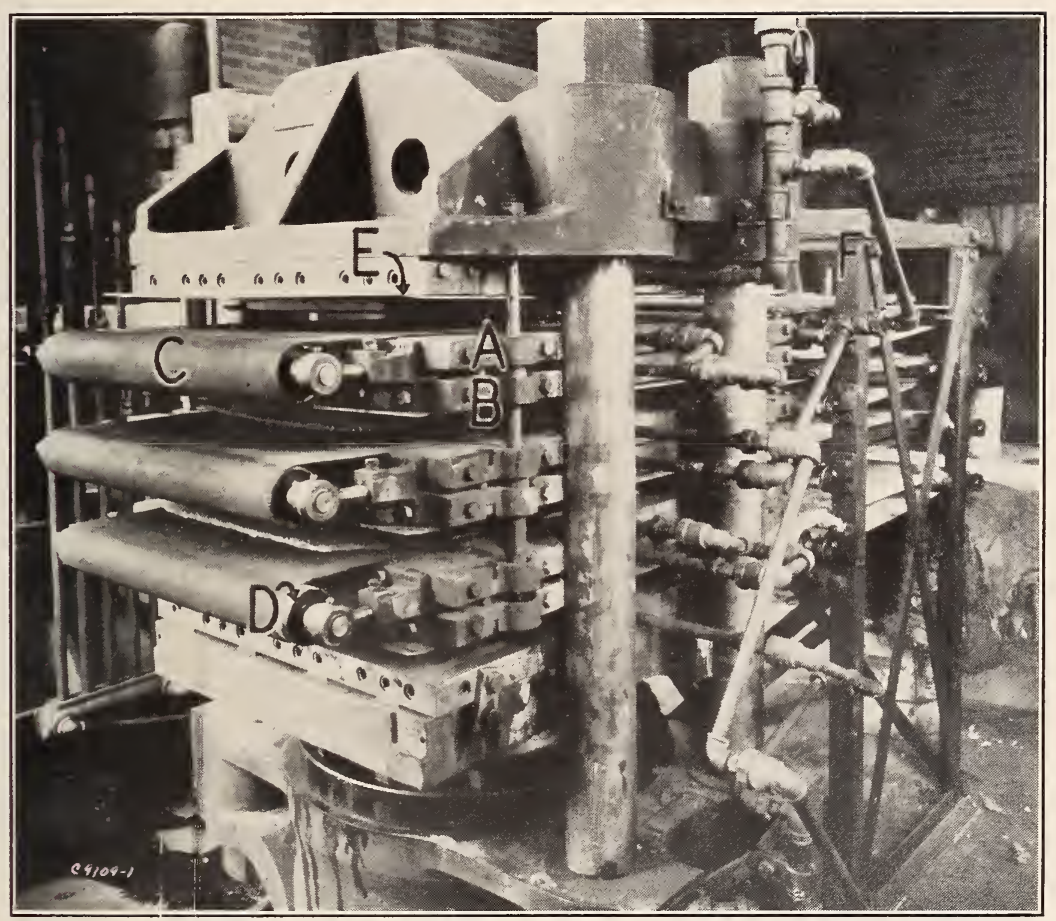

FIgURE 1.-Split-platen press and loading device.

A, B, Platen sections; C, wire screen; D, screen rolls; E, steel plate; F, loading rack. 



\section{EQUIPMENT}

The equipment consisted of a shredder, cookers, rod mill, washer, jordan, suction mold, and forming machine, which have been described in a previous article,${ }^{11}$ and, in addition, an attrition mill and hydraulic presses.

The attrition mill consisted essentially of two 24-in. steel disks mounted face to face on separate shafts and enclosed within a steel housing. When operating, the disks rotated in opposite directions at approximately $1,800 \mathrm{rpm}$. The degree of disintegration of the stalks was controlled by increasing or decreasing the compression of springs acting on one of the rotating disks, which made the faces of the disks rub with greater or less pressure on the material passing between them. Hydraulic presses, with heated platens, were used for pressing and drying the mats. The split-platen press with a loading device, designed ${ }^{12}$ particularly for this work, is shown in figure 1. This press was the standard type with four steel platens cored with steam ducts. Steam was admitted through hinged inlet pipes. Each platen was built in two horizontal 30- by 39 -in. sections, $A$ and $B$, with a $1 \frac{1}{4}$ in. space between them. An individual continuous screen belt passed over the top of section $A$ and returned through the space between sections $A$ and B. Section $A$ of each platen was drilled with $1 / 32$-in. holes on 2-in. centers. Section $B$ of each platen was faced with a polished stainless-steel plate $\mathrm{E}$. The continuous screen belts C, were of stainless steel, spiral-weare wire supported on guide rolls $\mathrm{D}$, which were mounted on the front and back of every platen. Each continuous screen belt was driven from the front roll and synchronized with a continuous canvas belt of a corresponding shelf on the loading rack $\mathrm{F}$.

\section{EXPERIMENTAL MANUFACTURE OF BOARD}

\section{PREPARATION OF STALIS}

After breaking open the bales, the stalks were reduced to lengths of 3 or 4 in. in an ensilage cutter. The material was then ready for the pulping operation.

The reduction of the stalks to short lengths increased the cooker charge and aided in the handling of the rod mill feed. Baled stalks generally contained a considerable amount of dirt. In the procedure used in the experimental work, this material was largely remored by washing in a continuous, rotary washer after the rod milling. Other results have shown that the stalks can be washed cleaner by four to fire batch washes in a mixing tank following the cutting operation. In the commercial manufacture of insulating board from cornstalks, two additional machines have been found advantageous: a bale breaker to disintegrate frozen, mud-cake bales and to aid in feeding the cutter; and a magnetic separator to remove baling wire and scrap iron and thus increase the life of the cutter and refining machines.

11 O. R. Sweeney, C. E. Hartford, R. W. Richardson and E. R. Whittemore. Experimental Studies on the Production of Insulating Board from Cornstalks. Iowa State College Eng. Experiment Station Bul. 102 (1931).

13 Designed by O. R. Sweeney, C. Mr. McDowell, and T. R. Naffziger. 


\section{PULPING}

Two methods of pulping were investigated: (1) the prepared stalks were cooked and then refined mechanically; and (2) they were pulped by mechanical means alone.

Cooked pulps were prepared by charging cut stalks and water into the cooker. The cooker was brought up to temperature and maintained for a definite time. The charge was then drained and fed, together with water, into the rod mill. The discharge from this mill passed into a continuous rotary-screen washer where it was washed with additional water. The washed pulp and water were introduced into a mixing tank and pumped to the attrition mill or the steep-angled jordan refiner. After the refining, the pulp was sized in the beater or in mixing tanks.

A series of pressboards ranging from weak boards of low density to strong ones of high density was produced by varying the degree of cooking. Table 1 shows the range of the physical properties of the boards obtained when the stalks were pulped mechanically and also by increasingly severe cooks followed by mechanical refining. Only three conditions have been tabulated and they represent those most suitable for the production of boards of low, medium, and high density and strength. Chemical cooks, such as with lime, soda ash, and 2 to 4 percent of caustic soda, produce boards somewhat denser and stronger, but this is probably too costly a procedure for the small increase in strength.

In either process the mechanical refining is an important step. The machines adaptable to the close control of fiber quality, length, and softness, are not suited to the direct, single treatment of raw or lightly cooked stallss. It is better to partially reduce the material in one and finish the refining in another machine. The refining operation separates the stalks into crude fiber bundles, and cuts and softens them.

A number of machines were investigated to determine their suitability as primary refiners. Such machines must be able to handle the cut stalks and the beater, the swing-hammer mill, or the rod mill met this requirement. The rod mill produced a good pulp at a higher rate than the other two machines and combined continuous operation with low power consumption. It was selected as the most suitable for the initial refining. The output and the power consumption of the rod mill were investigated for different types of pulp. In treating uncooked and pressure cooked stalks, the power requirement per ton decreased from $168 \mathrm{kwhr}$ in the former case to $113 \mathrm{kwhr}$ in the latter and the output increased from 0.10 to 0.15 ton per hour.

TABLE 1.-Yields and physical properties of unsized pressboard obtained under different cooking conditions

\begin{tabular}{|c|c|c|c|c|c|c|}
\hline \multirow{3}{*}{ Cooking treatment } & \multicolumn{2}{|c|}{$\begin{array}{l}\text { Yield on original } \\
\text { stalks } 1\end{array}$} & \multicolumn{4}{|c|}{ Range of physical properties } \\
\hline & \multirow{2}{*}{$\begin{array}{c}\text { After } \\
\text { cooking }\end{array}$} & \multirow{2}{*}{$\begin{array}{l}\text { After } \\
\text { rodmilling } \\
\text { and } \\
\text { washing }\end{array}$} & \multirow{2}{*}{ Density } & \multirow{2}{*}{$\begin{array}{l}\text { Modulus of } \\
\text { rupture }\end{array}$} & \multicolumn{2}{|c|}{ Moisture absorption 2} \\
\hline & & & & & $1 / 2 \mathrm{hr}$ & $24 \mathrm{hr}$ \\
\hline $\begin{array}{l}\text { None } \\
4 \mathrm{hr} \text { at } 82 \text { to } 100^{\circ} \mathrm{C}\end{array}$ & $\begin{array}{r}\% \\
100 \\
75 \text { to } 87 \\
68 \text { to } 85\end{array}$ & $\begin{array}{c}\% \\
74 \text { to } 80 \\
62 \text { to } 68 \\
54 \text { to } 48\end{array}$ & $\begin{array}{c}\mathrm{lb} / \mathrm{ft} \mathrm{t}^{3} \\
39 \text { to } 48 \\
50 \text { to } 58 \\
52 \text { to } 65\end{array}$ & $\begin{array}{c}\text { lb/in }{ }^{2} \\
2,040 \text { to } 4,000 \\
3,200 \text { to } 4,400 \\
5,000 \text { to } 7,500\end{array}$ & $\begin{array}{c}\% \\
11 \text { to } 26 \\
11 \text { to } 24 \\
11 \text { to } 15\end{array}$ & $\begin{array}{c}\% \\
79 \text { to } 110 \\
70 \text { to } 84 \\
58 \text { to } 80\end{array}$ \\
\hline
\end{tabular}

1 Oven-dry basis. Increase in weight after they had been immersed in water for the time indicated. 
Of the machines suitable for the second-stage refining, the attrition mills produced pulps which were properly rubbed and brushed, and also exerted the slight cutting action desired. The disk type of mill described in the equipment section and the steep-angled jordan gave suitable pulps, consumed less power than the other types and gave higher outputs. A comparison of power requirement and rate of refining was made between the two machines, but because of the difference in size definite conclusions could not be drawn as to their relative efficiency.

\section{FORMING}

For some test boards the mats were formed in a stationary mold, but were generally made on a continuous board-forming machine. ${ }^{13}$ This was a modified papermaking machine with a head box, illustrated in figure 2. The prepared pulp, at about 3-percent consistency, was pumped into the rear section of the head box. The force of the discharge was broken by the baffies and the forward speed was gradually decreased by the successively wider openings between them. The mat formed on the wire passed between press rolls and left the

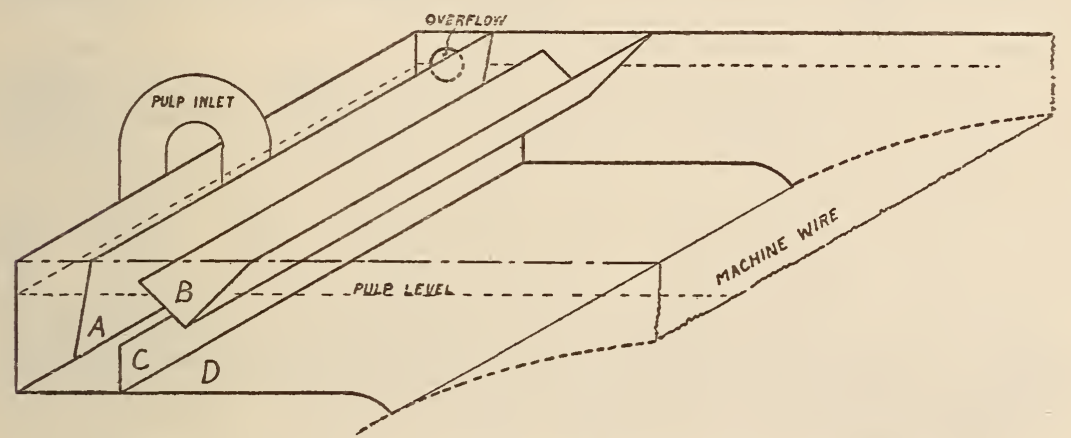

FIGURE 2.-Forming machine head box, showing baffe arrangement.

machine with a moisture content of approximately 75 percent. The continuous sheet was cut into 2.5 to $3 \mathrm{ft}$ lengths. The maximum thickness of mat that could be formed on the machine without crushing ${ }^{14}$ in the press rolls was approximately 3 in. This varied slightly according to the "slowness" of the stock.

\section{PRESSING AND DRYING}

The mat sections from the forming machine, with 20-mesh screens on both sides, were introduced into an unheated, hydraulic press. The pressure was brought up slowly to about $400 \mathrm{lb} / \mathrm{in}^{2}$ and held for 4 or $5 \mathrm{~min}$. The pressure was released and the mat, with one side covered by a 20 -mesh screen and the other by a polished metal plate, was placed in a heated hydraulic press, pressure applied, and the board allowed to dry.

13 O. R. Sweeney, C. E. Hartford, R. W. Richardson, and E. R. Whittemore, Experimental Studies on the Production of Insulating Board from Cornstalks. Iowa State College Eng. Experiment Station Bul. $102(1931)$.

11 "Crushing" is a term applied to the phenomenon of broken mat formation which occurs when water is expressed too rapidly by roll or flat presses. 
The important factors in the pressing and drying of pressboard were found to be initial moisture, pressure, temperature, thickness of the board, type of pulp, and the mesh and weave of the screen. These factors were investigated separately, as far as possible, to determine their relative effects on the time of drying and the strengths of the boards.

\section{(a) INITIAL AND FINAL THICKNESS}

It was found that the relation of the thickness of the initial mat to that of the final board has no direct bearing on the time required to dry the board nor on the strength of the final product. The initial thickness is of importance, however, when the working space is taken into consideration in designing the press. The data in tables 2 and 3 show that the ratio of the initial to the final thickness is fairly constant for wide ranges of thickness, moisture content, and different types of pulp. The results shown in table 2 were obtained by pressing two or more wet mats together to form single boards and those listed in table 3 were obtained from single mats.

TABLE 2.-Effects of thickness on compression during drying mechanical-news pulp ${ }^{1}$

\begin{tabular}{|c|c|c|c|}
\hline Number of mats & $\begin{array}{c}\text { Total } \\
\text { original } \\
\text { thickness }\end{array}$ & $\begin{array}{c}\text { Final } \\
\text { thickness }\end{array}$ & $\begin{array}{l}\text { Decrease in } \\
\text { original } \\
\text { thickness }\end{array}$ \\
\hline $\begin{array}{l}2 \\
4 \\
5\end{array}$ & $\begin{array}{l}\text { in. } \\
238 \\
234 \\
4 \\
5\end{array}$ & $\begin{array}{r}\text { in. } \\
0.28 \\
.39 \\
.58 \\
.73\end{array}$ & $\begin{array}{r}\% \\
85.8 \\
85.8 \\
85.5 \\
85.4\end{array}$ \\
\hline
\end{tabular}

1 Mechanical-news pulp consists of about 82 percent of mechanicol cornstalk pulp and 18 percent of pulped newspapers. The boards prepared from this pilp correspond in their physical properties to boards prepared from cornstalk pulp cooked under atmospheric pressure. The addition of pulped newspapers to mechanical cornstalk pulp reduces the dusting properties of the boards.

2 The equipment available limited the thickness of a single mat to that which would produce pressboard of 0.2 in. final thickness.

TABLE 3.-Effects of moisture content on compression during drying

[Basic pulp types]

\begin{tabular}{|c|c|c|}
\hline Pulp type & $\begin{array}{c}\text { Initial } \\
\text { moisture }\end{array}$ & $\begin{array}{l}\text { Decrease in } \\
\text { thickness }\end{array}$ \\
\hline $\begin{array}{l}\text { Mechanical } \\
\text { Do }\end{array}$ & $\begin{array}{r}\% \\
\quad 73.5 \\
\quad 33.0\end{array}$ & $\begin{array}{ll} & \\
& 85.8 \\
& 84.2\end{array}$ \\
\hline $\begin{array}{l}\text { Mechanical-news } \\
\quad \text { Do }\end{array}$ & $\begin{array}{l}82.5 \\
56.0\end{array}$ & $\begin{array}{l}83.8 \\
82.8\end{array}$ \\
\hline $\begin{array}{l}\text { Cooked.......... } \\
\text { Do }\end{array}$ & $\begin{array}{l}80.0 \\
73.0\end{array}$ & $\begin{array}{l}85.9 \\
85.6\end{array}$ \\
\hline
\end{tabular}

(b) INITIAL MOISTURE

A series of mats was prepared from mechanical pulps which contained differing percentages of water. Those having above 54 percent of moisture had been subjected to different pressures to express the water, and those having less than 54 percent were prepared by pressing followed by treatments in a hot-air drier. The results of these experi- 
ments, table 4 , indicated a decrease in modulus of rupture with a decrease in initial moisture.

TABLE 4.-The effect of initial moisture on the modulus of rupture of mechanical pulp boards

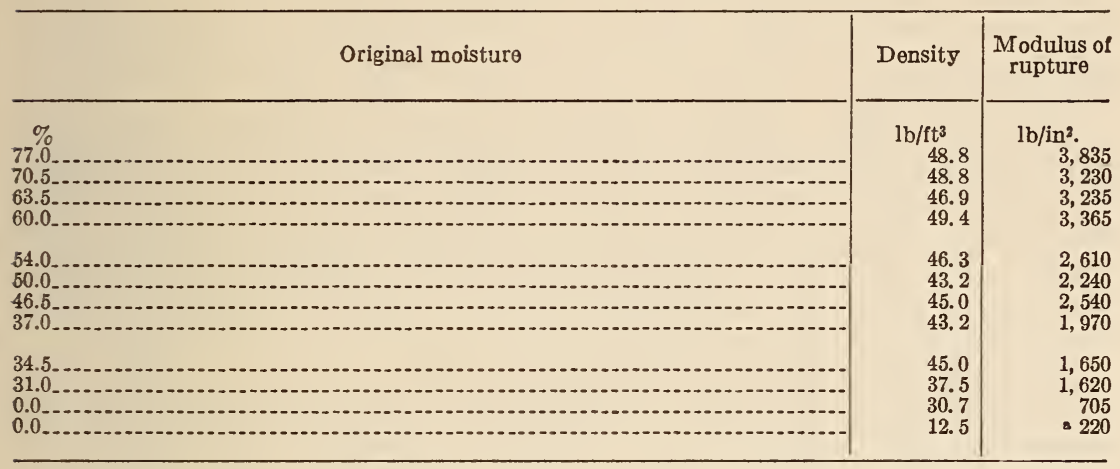

a No pressure was applied to this board in the hot press. The other boards in this study were dried in the bot press under a pressure of about $200 \mathrm{lb} / \mathrm{in}^{2}$.

A smooth curve, drawn through a plot of the modulus versus percentage initial moisture, indicated that, in its upper portion, the percentage decrease in moisture was approximately equal to the percentage decrease in modulus. Therefore, to facilitate the handling and storing of the wet mats from the forming machine, they were pressed for 4 to $5 \mathrm{~min}$. between two wire screens at 400 to 500 $\mathrm{lb} / \mathrm{in}^{2}$. in an unheated hydraulic press. This reduced their initial moisture content from approximately 75 to 60 percent. This initial pressing also made it possible to bring the mats up to pressure more rapidly in the hot press without increasing the danger of crushing them. The use of cold-pressing in commercial practice would depend on whether the saving in operating time and steam consumption in the hot presses offset the cost of cold-pressing and loss in strength.

(c) DRYING

(1) Pressure and temperature.-The relationship between the strength of the board and the pressure applied to it during the drying process is given for two different types of pulp in table 5. The data indicate that maximum strength results at about $500 \mathrm{lb} / \mathrm{in}^{2}$.

TABLE 5.-Effect of pressure on the strength and density of boards from cooked and mechanical pulps

\begin{tabular}{|c|c|c|c|}
\hline Туре of pulp & $\begin{array}{l}\text { Drying } \\
\text { pressure }\end{array}$ & Density & $\begin{array}{l}\text { Modulus } \\
\text { of rupture }\end{array}$ \\
\hline Cooked & $\begin{array}{l}795 \\
706 \\
618 \\
530 \\
441 \\
353\end{array}$ & $\begin{array}{l}\mathrm{lb} / \mathrm{ft}^{3} \\
64.1 \\
67.4 \\
64.8 \\
65.5 \\
61.3 \\
57.1\end{array}$ & $\begin{array}{r}\mathrm{lb} / \mathrm{in}^{2} . \\
6,030 \\
7,050 \\
6,830 \\
7,230 \\
7,500 \\
6,270\end{array}$ \\
\hline Mechanical........... & $\begin{array}{l}700 \\
500 \\
300 \\
100\end{array}$ & $\begin{array}{l}64.0 \\
61.7 \\
55.9 \\
45.4\end{array}$ & $\begin{array}{l}3,340 \\
3,590 \\
3,000 \\
2,040\end{array}$ \\
\hline
\end{tabular}


The temperature used for drying pressboards throughout this work was about $150^{\circ} \mathrm{C}$ or 50 to $55^{\circ} \mathrm{lb}$ gage on the steam presses. Some experiments were conducted on temperature effects but the evidence was not conclusive. In some cases, it was found that the modulus was decreased slightly in boards dried at 160 to $165^{\circ} \mathrm{C}$ and, in a few cases, the surfaces of the boards were scorched slightly by overdrying. In the case of wet-mat sizing, the boards dried at $150^{\circ} \mathrm{C}$ had improved moisture resistance. (See table 7.)

(2) Drying time and measurements. - The determination of the drying time for pressboards was found to be necessary for two reasons: first, that slightly underdried boards were blistered by the expansion of entrapped steam or moisture when the pressure was released; and second, that overdrying consumed steam and mill space. Overdrying the baards for $30 \mathrm{~min}$ seemed to cause no perceptible improvement or deterioration on the resulting product.

Two general methods for the determination of the dry point were investigated. One was the compilation of an actual time curve for boards of like pulp types and varying thicknesses. The other was the end-point method. ${ }^{15}$

The first method prored to be unsatisfactory, as the data showed wide variations in the drying time. Of the end-point methods, the measurement of electrical resistance of the board was best.

(3) Mechanical aids for the escape of steam.-The use of mechanical aids to permit the rapid escape of steam was necessary for economical drying. After experimenting with various types of screens and perforated plates, it was found that a 20 -mesh screen against one face of the board gave the best results. Coarse-mesh screens reduced the drying time but increased the roughness and dusting of the board surface. Screens on both surfaces of the boards greatly reduced the drying time, but roughened both sides. Spiral-weave wire, while more serviceable as a conveyor, imparted rery rough suriaces to the boards.

\section{SIZING FOR WATER RESISTANCE}

Inasmuch as untreated pressboards made from cornstalk fibers absorb moisture rapidly, and as a result warp and lose strength rapidly, some kind of sizing is necessary to obtain moisture resistance. This may be accomplished by beater sizing, wet-mat sizing, surface sizing, or by solvent sizing, and these methods were studied.

\section{(a) BEATER OR TANK SIZING}

The sizing material was added to a water suspension of the fibers in a beater or tank and precipitated with a suitable chemical after thorough mixing. A number of different sizing materials were used and the best results obtained are shown in table 6 . The best water resistance, without excessive loss of strength, was obtained with the commercial parafin emulsion $\mathrm{P}-1$, although comparable results were obtained with rosin sizing by the method commonly employed in the beater sizing of paper. The boards sized with asphalts of different melting points showed comparable water resistance but lost about 50 percent of their original strength.

16 E. R. Whittemore, C. B. Overman, and Baker Wingfield. Semicommercial drying of pressboard by measuring its electrical resistance. Ind. Eng. Chem. 27, 831 (1935). 
TABLE 6.-Beater sizing

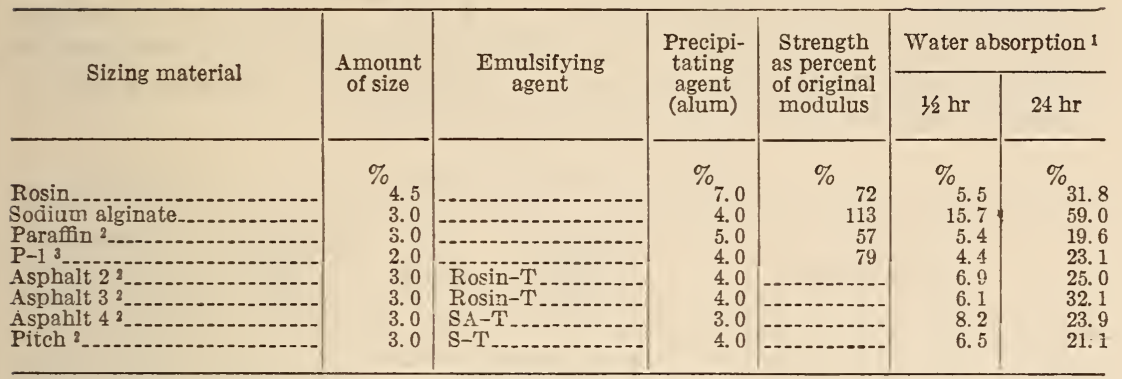

1 All water absorptions in tables 6,7 , and 8 are given as weight percent.

2 Emulsions prepared in the laboratory containing 25 percent of size:

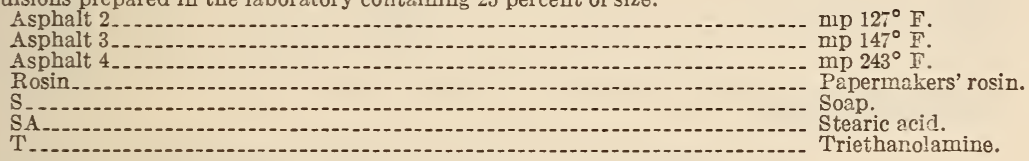

3 Commercial emulsion containing 38 percent of paraffin.

\section{(b) WET-MAT SIZING}

Unsized wet mats were cold-pressed to about 65-percent of moisture, covered with sizing material, and then dried under pressure at different temperatures. Table 7 lists the results obtained with paraffin oil, paraffin, and halogenated naphthalene. Paraffin at $150^{\circ} \mathrm{C}$, as in the beater-sizing tests, gave the best moistureproofing combined with low loss in strength.

TABLE 7.-Wet-mat sizing

\begin{tabular}{|c|c|c|c|c|c|}
\hline \multirow{2}{*}{ Sizing material } & \multirow{2}{*}{$\begin{array}{c}\text { Press } \\
\text { tempera- } \\
\text { ture }\end{array}$} & \multirow{2}{*}{ Density } & \multirow{2}{*}{$\begin{array}{l}\text { Strength } \\
\text { as percent } \\
\text { of original } \\
\text { modulus }\end{array}$} & \multicolumn{2}{|c|}{ Water absorption } \\
\hline & & & & $1 / 2 \mathrm{hr}$ & $24 \mathrm{hr}$ \\
\hline Paraffin & ${ }^{\circ} \mathrm{C}_{150}$ & $\begin{array}{l}\mathrm{lb} / \mathrm{ft}^{3} \\
63.7\end{array}$ & $\%_{75.2}$ & $\%_{4.8}$ & ${ }^{\%}{ }_{21.6}$ \\
\hline $\begin{array}{l}\text { Do....... } \\
\text { Do..... }\end{array}$ & $\begin{array}{l}140 \\
130\end{array}$ & $\begin{array}{l}63.1 \\
61.3\end{array}$ & $\begin{array}{l}70.0 \\
64.5\end{array}$ & $\begin{array}{l}6.5 \\
6.5\end{array}$ & $\begin{array}{l}33.8 \\
35.9\end{array}$ \\
\hline Paraffin oil & $\begin{array}{l}150 \\
130\end{array}$ & $\begin{array}{l}68.9 \\
60.2\end{array}$ & $\begin{array}{l}59.1 \\
48.4\end{array}$ & $\begin{array}{l}9.2 \\
8.6\end{array}$ & $\begin{array}{l}36.8 \\
28.5\end{array}$ \\
\hline Halogenated naphthalene.. & $\begin{array}{l}150 \\
140\end{array}$ & $\begin{array}{l}62.9 \\
62.8\end{array}$ & $\begin{array}{l}89.4 \\
90.0\end{array}$ & $\begin{array}{l}39.2 \\
44.0\end{array}$ & $\begin{array}{l}83.9 \\
89.8\end{array}$ \\
\hline
\end{tabular}

(c) SURFACE SIZING

Only one surface-sizing experiment was made. Unsized, finished boards were covered with bakelite varnish and dried in a heated press. The boards thus treated had a moisture absorption of about 11 and 22 percent for $1 / 2$ and $24 \mathrm{hr}$, respectively, and showed an increase of about 10 percent in the modulus of rupture over the original boards. The bakelite imparted a smooth, glossy finish to the surface of the boards and greatly improved their appearance.

(d) SOLVENT SIZING

The sizing material was dissolved in suitable solvents and the unsized, finished boards were impregnated with the solutions. The solvents were removed by drying at $105^{\circ} \mathrm{C}$ for $30 \mathrm{~min}$. 
The data in table 8 show that boards impregnated with a solution of paraffin in carbon tetrachloride and dried were more moistureresistant than when sized by any other method and were comparable with the best commercial products. There was no apparent loss in strength in the boards from the sizing operation.

TABLE 8.-Solvent sizing

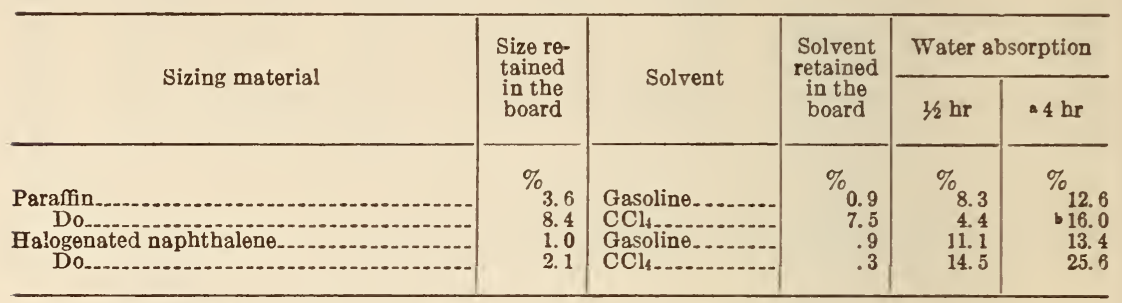

a 4 -hr absorption is equal to approximately $4 / 7$ of the $24-\mathrm{hr}$ absorption value.

- 24-hr absorption value.

\section{SUMMARY AND CONCLUSIONS}

1. A process for producing pressboard from cornstalks is outlined which consists in stalk preparation, pulping, forming, pressing and drying under pressure, and sizing.

2. The reduction of the stalks to short lengths in a cutter increased the output of the cookers and aided in the feeding of the pulping machines.

3. The removal of dirt, wire, etc., from the stalks is advantageous in lengthening the life of the pulping machines and improving the board.

4. A wide range of board strengths was obtained from cornstalk pulps: the highest strength from those cooked under pressure; medium strength from those cooked at atmospheric pressure; and low strength from those prepared mechanically.

5. A two-stage mechanical refining in separate machines appears to be better than single-stage refining in the preparation of uniform pulps.

6 . It is possible to reduce by pressure the moisture content of the wet mats by 20 percent. This lowers the board strength by the same amount, but it should reduce the steam consumption in the drying process.

7. Boards from similar pulps were of maximum strength when dried under pressures of approximately $500 \mathrm{lb} / \mathrm{in}^{2}$.

8. A drying temperature of approximately $150^{\circ} \mathrm{C}$ is recommended.

9. The drying time for pressboards varied, in general, with the thickness of the final product; however, to prevent losses from blistering and waste of time in overdrying, a more dependable criterion than thickness should be employed.

10. The electrical-resistance method for determining the drying time is recommended.

11. The most effective of the moisture-proofing methods investigated was that of solvent sizing of the finished board, but it was comparatively expensive. Beater or tank sizing with paraffin or rosin gave boards which absorbed approximately 20 to 30 percent of water when immersed for $24 \mathrm{hr}$.

Washington, May 12, 1936. 


